\title{
Antenatal counselling as a tool to increase acceptability of postpartum intrauterine contraceptive device insertion in a tertiary care hospital
}

\author{
Neelima Agarwal*, Manisha Gupta, Amita Sharma, Raksha Arora
}

\begin{abstract}
Department of Obstetrics and Gynaecology, Santosh Medical College \& Hospital, Santosh University, Ghaziabad, Uttar Pradesh, India
\end{abstract}

Received: 07 June 2015

Accepted: 10 July 2015

\section{*Correspondence:}

Dr. Neelima Agarwal,

E-mail: agarwalneelima2@gmail.com

Copyright: () the author(s), publisher and licensee Medip Academy. This is an open-access article distributed under the terms of the Creative Commons Attribution Non-Commercial License, which permits unrestricted non-commercial use, distribution, and reproduction in any medium, provided the original work is properly cited.

\begin{abstract}
Background: Acceptance of postpartum intrauterine device (IUD) insertions in women in Uttar Pradesh is low. In response to the concept that a good postpartum programme should begin prenatally, this study was designed to determine whether the provision of expert contraceptive counselling during the antenatal period would have an impact on its uptake as compared to women who were counselled in post partum period.

Methods: Expert contraceptive counselling was given to 264 and154 women during their antenatal visits and postpartum hospitalization, respectively. Acceptors received IUCDs within $48 \mathrm{~h}$ of delivery in the case of vaginal delivery or transcesarean insertion in case of abdominal delivery. The acceptance rate of PPIUCD and the percentage of actual insertions were recorded. The causes of refusal were also recorded.

Results: Among the 264 couples counselled in antenatal period 116 (43.9\%) had PPIUCD insertion. Among the 154 unbooked women who were counselled postpartum only PPIUCD was inserted in $36(23.4 \%)$ women. PPIUCD insertion was significantly high in women receiving expert counselling during antenatal period as compared to the women who were counselled in postnatal period $(\mathrm{p}<0.001)$. Family refusal, No knowledge of PPIUCD and preference for another contraceptive methods were the most common reasons for refusing the use of PPIUCD.

Conclusion: Acceptability of PPIUCD insertion was high in women counselled in antenatal period. Hence, it is suggested that counselling for PPIUCD should start in antenatal period.
\end{abstract}

Keywords: PPIUCD insertion, Acceptability, Antenatal counselling

\section{INTRODUCTION}

An increase in contraceptive use during the postpartum period should substantially reduce rates of maternal and infant mortality by preventing unplanned and unwanted pregnancies, and spacing new pregnancies to at least two years after the previous birth. ${ }^{1}$

Postpartum intrauterine contraceptive device (PPIUCD) insertion is a component of postpartum family planning and can serve for spacing. According to the World Health Organization Medical Eligibility Criteria, an IUCD can be inserted in the 48 hours postpartum. ${ }^{2}$ It is effective for 5 years $(\mathrm{Cu} 375)$ or 10 years $(\mathrm{Cu} 380 \mathrm{~A})$.

According to 2005-2006 National Family Health Survey III (NFHS III) data from Uttar Pradesh, India, two of every three postpartum mothers were not using any family planning method. Three out of every four postpartum women expressed an unmet need for family planning. Unmet need decreases but remains high throughout the first year postpartum. Almost $60 \%$ women still desired to space or limit subsequent births by the end of the year ${ }^{3}$. Studies have shown that, in general, women 
who desire another child do not want to conceive for at least 18 months after their last birth; this holds true in India as well. However, this desire to delay pregnancy often does not translate into the use of contraceptives. IUCDs are used by only two percent of current users of contraception in India. ${ }^{3}$ The current national strategy in India is for increasing IUCD uptake. The available target to cover with PPIUCD as a method of contraception has expanded in the recent past; since there is a 10 fold increase in women delivering in hospitals due to maternity benefit scheme. ${ }^{4}$

Counselling about spacing methods can be timeconsuming and providers must work against the myths and misconceptions about family planning use that are prevalent in the community. In a study even in the intervention area, the majority of women reported condoms as the postpartum contraceptive method they used $^{4}$.There is a lack of decision-making power about contraceptive use among young women. ${ }^{5}$ Improved interpersonal communications in the health facility at the time of ANC check-ups may be an ideal approach to encouraging women for PPIUCD insertion. Women who receive antenatal care (ANC) services are more likely to use postpartum family planning. ${ }^{3}$

ANC services allow multiple opportunities to address the woman's concerns and answer her questions. As well, it allows for a discussion with the husband or other family members which is considered to be an important part of the counselling process in India.

In response to the concept that a good postpartum program should begin prenatally, this study was designed to determine whether the provision of expert contraceptive counselling during the antenatal period would have an impact on acceptability of PPIUCD insertion.

Our specific aims were to determine the demographic characteristics of women who accepted PPIUCDs after contraceptive counselling during the antenatal period and women who were unbooked and received postnatal counselling. The reasons for refusal in both the group were also noted. We also analysed the difference in PPIUCD insertion, if any, between those two groups.

\section{METHODS}

This prospective observational cohort study was conducted in the Department of Obstetrics \& Gynaecology, Santosh Medical College Hospital, Santosh University, Ghaziabad, U.P. between January 2014 to June 2015 after getting approval from the ethical committee.

After informed consent, those women who met the eligibility criteria for PPIUCD insertion were included in the study.

\section{Inclusion criteria}

- Pregnant Women coming for antenatal check-up and eligible for PPIUCD insertion.

- Unbooked women delivered in our hospital and meeting all the eligibility criteria for post partum IUCD Insertion.

\section{Exclusion criteria: women having-}

a. Chorioamnionitis or Puerperal sepsis.

b. Prolonged rupture of membranes of $>18 \mathrm{hrs}$

c. Extensive genital trauma.

d. Unresolved PPH

e. Any abnormality of uterus or a large fibroid distorting its cavity

f. Pelvic Inflammatory Disease

g. Malignant or benign trophoblastic disease

h. HIV/AIDS

Four hundred pregnant women, in the reproductive age group 15-45 years, attending Santosh Medical college Hospital, Ghaziabad, Uttar Pradesh, during their antenatal visit were interviewed. Among them 264 couples were found suitable and counselled for PPIUCD insertion along with their family members also.

One hundred fifty four unbooked women who delivered in our hospital and considered suitable for insertion were also counselled in the same manner postpartum for PPIUCD insertion.

Their demographic characteristic and obstetric history were noted. We also explored the reason for unwillingness for PPIUCD insertion among the couples refusing for PPIUCD insertion. Acceptors received IUCDs $(\mathrm{Cu} 375)$ within $48 \mathrm{~h}$ of delivery in the case of vaginal delivery or transcesarean insertion in case of abdominal delivery.

Data was analyzed in Excel 2007. Descriptive statistics, chi-square tests were done and significance of tests was decided at $\mathrm{p}$-value $<0.05$.

\section{RESULTS}

\section{Couples counselled during antenatal period}

Out of the 264 couple counselled in antenatal period 186 $(70.5 \%)$ couples agreed for insertion of PPIUCD and the rest declined (Table 1).

Among the women counselled $57.2 \%$ were of age group 20-25 yrs, 37.1\% were of age group 26-30 yrs and rest were of of 31yers of age and above. Among the women who agreed for PPIUCD insertion, 61.3\% were from age group 20-25 years (Table 1).

Among the women who agreed after counselling $73.2 \%$ were educated and $59.1 \%$ of women belonged to uppermiddle and upper class (Table 1). 
Out of the the 264 women who were counselled 196 women delivered in our hospital and among them PPIUCD was inserted in $116(43.9 \%)$ women and it included 163 women out of 186 women who agreed for PPIUCD insertion at the time of counselling. The number of women who agreed earlier and declined postpartum insertion of IUCD were $47(28.8 \%)$ (Figure 1$)$.

Table 1: Socio-demographic characteristics of women counselled for PPIUCD in antenatal period.

\begin{tabular}{|c|c|c|c|c|}
\hline Characteristics & $\begin{array}{l}\text { Total } \\
\text { Counselled } \\
\text { n(\%) }\end{array}$ & $\begin{array}{l}\text { Agreed } \\
\text { when } \\
\text { Counselled } \\
\mathbf{n}(\%)\end{array}$ & $\begin{array}{l}\text { Declined } \\
\text { when } \\
\text { Counselled } \\
\mathbf{n}(\%)\end{array}$ & $\begin{array}{l}\text { PPIUCD } \\
\text { inserted } \\
\mathbf{n}(\%)\end{array}$ \\
\hline $\begin{array}{l}\text { Total no. of } \\
\text { women }\end{array}$ & 264 & $186(70.5)$ & $78(29.5)$ & $\begin{array}{l}116 \\
(43.9)\end{array}$ \\
\hline Age $n \pm S D$ & $25.6 \pm 3$ & $25.4 \pm 2.9$ & $25.9 \pm 3.4$ & $\begin{array}{l}25.5 \pm \\
2.7\end{array}$ \\
\hline $20-25$ & $151(57.2)$ & $114(61.3)$ & $37(47.4)$ & $69(59.5)$ \\
\hline $26-30$ & $98(37.1)$ & $62(33.3)$ & $36(46.2)$ & $42(36.2)$ \\
\hline $31-35$ & $11(4.2)$ & $8(4.3)$ & $3(3.8)$ & $4(3.4)$ \\
\hline$\geq 36$ & $4(1.5)$ & $2(1.1)$ & $2(2.6)$ & $1(0.8)$ \\
\hline \multicolumn{5}{|l|}{$\begin{array}{l}\text { Educational } \\
\text { Status }\end{array}$} \\
\hline $\begin{array}{l}\text { No Formal } \\
\text { Education }\end{array}$ & $94(35.6)$ & $50(26.8)$ & $44(56.4)$ & $7(6)$ \\
\hline Primary & $77(29.2)$ & $57(30.6)$ & $20(74)$ & $46(39.7)$ \\
\hline Secondary & $69(26.1)$ & $58(31.2)$ & $11(25.6)$ & $43(37.1)$ \\
\hline $\begin{array}{l}\text { Higher } \\
\text { Education }\end{array}$ & $24(9.1)$ & $21(11.3)$ & $3(3.8)$ & $20(17.2)$ \\
\hline \multicolumn{5}{|l|}{ Religion } \\
\hline Hindu & $214(80.1)$ & $157(84.4)$ & $57(73.1)$ & $92(79.3)$ \\
\hline Muslim & $50(19.9)$ & $29(15.6)$ & 21(26.9) & $24(20.7)$ \\
\hline \multicolumn{5}{|l|}{ Parity } \\
\hline 0 & $60(22.7)$ & $36(19.4)$ & $24(30.8)$ & \\
\hline 1 & $136(51.6)$ & $104(55.9)$ & $32(41.1)$ & $13(11.2)$ \\
\hline 2 & $60(22.7)$ & $39(21)$ & 21(26.9) & $67(57.8)$ \\
\hline$\geq 3$ & $8(3)$ & $7(3.7)$ & $1(1.2)$ & $36(31)$ \\
\hline \multicolumn{5}{|l|}{$\begin{array}{l}\text { Economic } \\
\text { Status }\end{array}$} \\
\hline $\begin{array}{l}\text { Lower Class } \\
\text { and Lower } \\
\text { middle class }\end{array}$ & $113(42.8)$ & $76(40.9)$ & $37(47.4)$ & 38 (32.8) \\
\hline $\begin{array}{l}\text { Middle, Upper } \\
\text { middle and } \\
\text { Upper Class }\end{array}$ & $151(57.2)$ & $110(59.1)$ & $41(52.6)$ & $78(67.2)$ \\
\hline
\end{tabular}

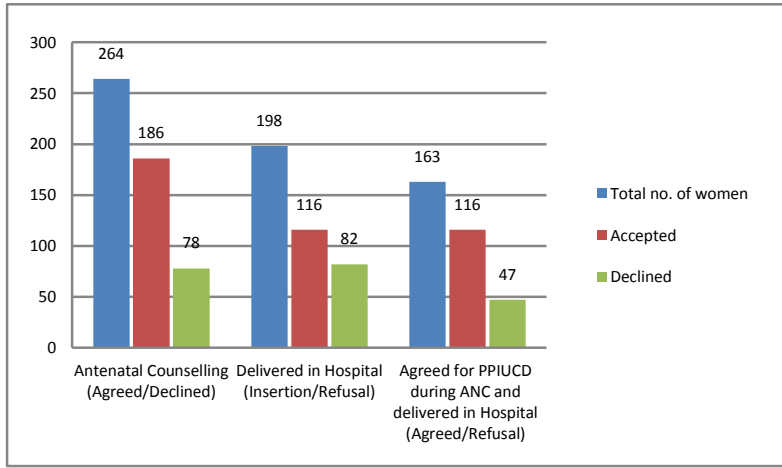

Figure 1: Acceptance of PPIUCD in women counselled during antenatal visits.

The commonest reason for non-acceptance of PPIUCD insertion by couples during antenatal counselling and the women who refused later was family refusal $(53.6 \%)$ (Figure 2).

\section{Counselled postpartum}

One hundred fifty four unbooked women who delivered in our hospital and found suitable for PPIUCD insertion were counselled for PPIUCD insertion along with their family members postpartum (Table 2).

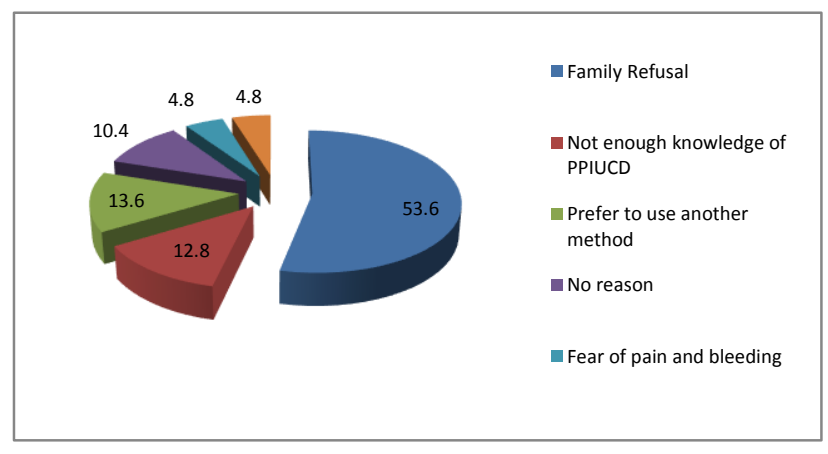

Figure 2: Reasons for non acceptance of PPIUCD in women counselled in antenatal period $(\%)$.

Table 2: Socio-demographic characteristics of women counselled for PPIUCD insertion postpartum.

\begin{tabular}{|c|c|c|c|}
\hline Characteristics & $\begin{array}{l}\text { Total } \\
\text { Counselled } \\
\text { n }(\%)\end{array}$ & $\begin{array}{l}\text { Declined } \\
\text { when } \\
\text { Counselled } \\
\text { n }(\%)\end{array}$ & $\begin{array}{l}\text { PPIUCD } \\
\text { Inserted } \\
\mathbf{n}(\%)\end{array}$ \\
\hline $\begin{array}{l}\text { Total no. of } \\
\text { women }\end{array}$ & 154 & $118(76.6)$ & $36(23.4)$ \\
\hline Age $n \pm S D$ & $26.5 \pm 3.7$ & $26.6 \pm 3.9$ & $26 \pm 3.2$ \\
\hline $20-25$ & $83(53.9)$ & $62(52.5)$ & $21(58.4)$ \\
\hline $26-30$ & $60(39)$ & $48(40.7)$ & $12(33.3)$ \\
\hline $31-35$ & $6(3.9)$ & $4(3.4)$ & $3(8.3)$ \\
\hline$\geq 36$ & $5(3.2)$ & $5(4.2)$ & 0 \\
\hline \multicolumn{4}{|l|}{$\begin{array}{l}\text { Educational } \\
\text { Status }\end{array}$} \\
\hline $\begin{array}{l}\text { No Formal } \\
\text { Education }\end{array}$ & $68(44.2)$ & $65(55.1)$ & $3(8.3)$ \\
\hline Primary & $49(31.8)$ & $35(29.7)$ & $14(38.9)$ \\
\hline Secondary & $23(14.9)$ & $8(6.8)$ & $15(41.6)$ \\
\hline $\begin{array}{l}\text { Higher } \\
\text { Education }\end{array}$ & $14(9.1)$ & $10(8.5)$ & $4(11.1)$ \\
\hline \multicolumn{4}{|l|}{ Religion } \\
\hline Hindu & $125(81.2)$ & $97(82.2)$ & $28(77.8)$ \\
\hline Muslim & $29(18.8)$ & $21(17.8)$ & $8(22.2)$ \\
\hline \multicolumn{4}{|l|}{ Parity } \\
\hline 1 & $123(79.9)$ & $101(85.6)$ & $22(61.1)$ \\
\hline 2 & $45(29.2)$ & $22(18.6)$ & $13(36.1)$ \\
\hline$\geq 3$ & $6(3.9)$ & $5(4.2)$ & $1(2.8)$ \\
\hline \multicolumn{4}{|l|}{$\begin{array}{l}\text { Economic } \\
\text { Status }\end{array}$} \\
\hline $\begin{array}{l}\text { Lower Class } \\
\text { and Lower } \\
\text { middle class }\end{array}$ & $65(42.2)$ & $54(45.8)$ & 11(30.6) \\
\hline $\begin{array}{l}\text { Middle, Upper } \\
\text { middle and } \\
\text { Upper Class }\end{array}$ & $89(57.8)$ & $64(54.2)$ & $25(69.4)$ \\
\hline
\end{tabular}


Among the 154 women who were counselled postpartum only PPIUCD was inserted in $36(23.4 \%)$ women. The most common reason for refusal was family refusal $(62.7 \%)$ (Figure 3).

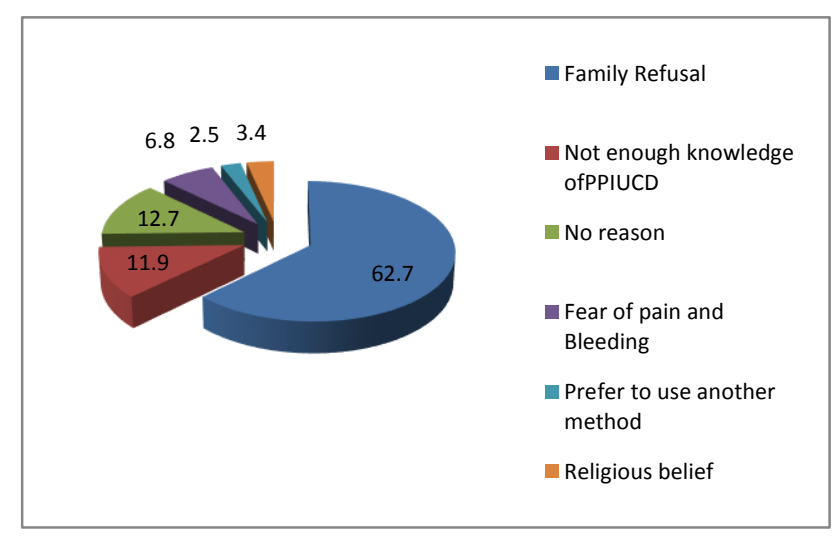

Figure 3: Reasons for refusal of PPIUCD in women counselled postpartum $(\%)$.

The demographic characteristic of both the groups were similar. About $46 \%$ of women of both the group combined, who accepted PPIUCD insertion, made their own decision to use a PPIUCD and $24.3 \%$ more decided after consulting their family members (Table 3 ).

\section{Table 3: Decision Making in PPIUCD Insertion $n=116$} +36 (152).

\begin{tabular}{|ll|}
\hline Self, alone n (\%) & $70(46.1)$ \\
\hline Self after consulting with Family n (\%) & $37(24.3)$ \\
\hline Husband n(\%) & $31(20.4)$ \\
\hline Mother in law $\mathrm{n}(\%)$ & $14(9.2)$ \\
\hline
\end{tabular}

PPIUCD insertion in women who received contraceptive counselling in antenatal period was $43.9 \%$ as compared to to women who were counselled in postpartum period which was $23.4 \%$ only and is highly significant $(\mathrm{p}<0.001)$.

\section{DISCUSSION}

In our study among the 264 couples counselled in antenatal period 116 (43.9\%) had PPIUCD insertion. Among the 154 unbooked women who were counselled postpartum only PPIUCD was inserted in $36(23.4 \%)$ women. PPIUCD insertion was significantly high in women receiving expert counselling during antenatal period as compared to the women who were counselled in postnatal period $(\mathrm{p}<0.001)$.

The postpartum phase is regarded as a time of vulnerability for mother and infant, and any perception that use of PPIUCD insertion might hinder their chance for future conception acts as a powerful disincentive for early postpartum use.

A plausible explanation of the relatively high acceptance of PPIUCD in the antenatally counselled women was that she along with her family members had time to think and discuss about it among themselves after receiving expert medical advice. A majority of the accepters rely on their physician and counselling of the couples during antenatal period helps.

A prospective cohort study in India found a significant increase $(61.8 \%$ versus $30.6 \%)$ in contraceptive use at 9 months postpartum by women in the intervention group compared with the control group. The intervention included an educational campaign carried out by community workers using leaflets, posters, wall paintings and booklets. The campaign addressed pregnant women, their husbands, mothers-in-law and community opinion leaders. ${ }^{4}$

A non-equivalent control group study found increased use of postpartum contraception following ANC counselling that included husbands. However, this article included little description of the intervention. ${ }^{6}$ A study from Delhi, which explored the reasons behind the low acceptance of PPIUCD in users, found that the most common reason affecting the readiness for PPIUCD insertion was lack of involvement of husband in counselling during antenatal period, regarding the need for birth spacing \& benefits of PPIUCD as an effective means of contraception right from the time of delivery. ${ }^{7}$

Acceptance of PPIUCD was very poor among the illiterate women in both the antenatally counselled and postnatally counselled group and it was $6 \%$ and $8.3 \%$ respectively. A large study from Uttar Pradesh looking at family planning among the urban poor showed that less educated women (1-11 years) living in both slum and non-slum areas are more likely to be sterilized, less likely to use other modern contraceptives, and more likely to have an unmet demand for family planning than more educated women (+12years of education) ${ }^{8}$

Our study result were also similar to a study done in Odisha by Mishra et al. ${ }^{9}$ where acceptance of PPIUCD was higher among women with Primary and Secondary education (28.56\% and 13.88), than those with no formal or higher education (7.75 and $8.21 \%$ ). Our study confirms the importance of education in deciding future pregnancy.

PPIUCD insertion was most common among women who were either nullipara or primipara during antenatal counselling (69\%) and among the primipara in the post natally counselled group $(62.8 \%)$. This finding is contrary to that of the study by Grimes et al. ${ }^{10}$ where they found higher acceptance in multiparous clients $(65.1 \%)$.

The commonest reason for declining PPIUCD insertion was family refusal $(53.6 \%)$ followed by preference for other methods $(13.6 \%)$ in women counselled in antenatal period. In unbooked patient the commonest reason for not accepting PPIUCD insertion was also family refusal $(62.7 \%)$ but was higher as compared to other group. This again highlights the importance of couple counselling in antenatal period. 
A study by Kumar et al. which covered a large sample of women from eight states of India found that while more than half of the women based their decision to use a PPIUCD based on discussing with multiple individuals, more than $70 \%$ of the women choosing to use a PPIUCD as a contraceptive method received PPFP counselling by a dedicated counsellor at the facilities, and many stated they made the own decision to use a PPIUCD before delivery, either during antenatal care or before delivery. ${ }^{11}$ In our study about $46 \%$ of women who accepted PPIUCD insertion, made their own decision to use a PPIUCD and $24.3 \%$ more decided after consulting their family members.

PPFP/PPIUCD services have been scaled up in 303 district hospitals in high focus states of Uttar Pradesh, Jharkhand, Bihar, Madhya Pradesh, Chhattisgarh, Rajasthan and Odisha till January 2014. Total cumulative number of PPIUCD insertions till January 2014 are 1,93,046 which is average $7 \%$ of deliveries at the identified facilities and merely $6 \%$ in Uttar Pradesh ${ }^{\mathbf{1 2}}$. The high acceptability in our study may be due to high number of educated and urban women participating in the study and also as a result of changing community perception towards this new alternative for Family Planning. It is important for the healthcare workers to provide informed and voluntary choices during ANC counselling and especially reaffirming their choice when they are in labour as we did in our study.

\section{CONCLUSION}

Both the acceptance and actual insertion of IUCD were high in women counselled in antenatal period. Hence, it is suggested that counselling for PPIUCD should start in antenatal period in a dedicated facility.

Funding: No funding sources

Conflict of interest: None declared

Ethical approval: The study was approved by the

Institutional Ethics Committee

\section{REFERENCES}

1. Vernon R. Meeting the Family Planning Needs of Postpartum Women. Stud Fam Plann. 2009;40(3):235-45.
2. World Health Organization: Medical Eligibility Criteria for Contraceptive Use. 4th edition. Geneva: World Health Organization; 2010.

3. International Institute for Population Sciences (IIPS), The Third National Family Health Survey (NFHS-3), India: 2005-06 (Mumbai: International Institute for Population Sciences, 2007).

4. Sebastian MP et al. Increasing postpartum contraception in rural India: evaluation of a community-based behaviour change communication intervention. International Perspectives on Sexual and Reproductive Health. 2012;38(2):68-77.

5. Stephenson R and Tsui AO. Contextual influences on reproductive health service use in Uttar Pradesh, India. Stud Fam Plann.2002;33(4):309-20.

6. Varkey LC et al. Involving men in maternity care in India. New Delhi, India, Population Council, 2004.Available at http://www. popcouncil.org/pdfs/ frontiers/ FR Final Reports/ India-MIM.pdf. Accessed on $2^{\text {nd }}$ June2015.

7. Priya et al. Exploring reasons behind Low acceptance for PPIUCD in postnatal women. New Indian Journal of Surgery. 2011;2(4):246.

8. Speizer IS, Nanda P, Achyut P, Pillai G, Guilkey DK. Family planning use among urban poor women from six cities of Uttar Pradesh, India. J Urban Health. 2012;89:639-58.

9. Mishra S: Evaluation of Safety, Efficacy, and Expulsion of Post-Placental and Intra-Caesarean Insertion of Intrauterine Contraceptive Devices (PPIUCD). JOGI. 2014;64(5):337-43.

10. Grimes D, Lopez LM, Schulz KF, Stanwood NL. Immediate post-partum insertion of intrauterine devices. Cochrane Database Syst Rev. 2010;12: CD003036.

11. Kumar et al: Women's experience with postpartum intrauterine contraceptive device use in India. Reproductive Health. 2014;11:32.

12. pdf.usaid.gov/ pdf_docs: Postpartum Insertion of IUCD: A Safe and Effective Contraceptive Option. Available at http://pdf.usaid.gov/pdf_docs/pa00jvv4. pdf accessed on $4^{\text {th }}$ June 2015.

Cite this article as: Agarwal N, Gupta M, Sharma A, Arora R. Antenatal counselling as a tool to increase acceptability of postpartum intrauterine contraceptive device insertion in a tertiary care hospital. Int J Reprod Contracept Obstet Gynecol 2015;4:1137-41. 